\title{
Evaluation of Antibiotic Use in Medical Ward of Fitche District Hospital, North Showa Zone, Oromia Region, Ethiopia
}

\author{
Addisu Alemayehu Gube ${ }^{1 *}$, Rufael Gonfa ${ }^{2}$ and Tarekegn Tadesse ${ }^{2}$
}

${ }^{1}$ Department of Nursing, College of Medicine and Health Sciences, Arbaminch University, Arbaminch, Ethiopia

${ }^{2}$ Department of Pharmacy, College of Medicine and Health Sciences, Ambo University, Ambo, Ethiopia

\begin{abstract}
Background: Antibiotic are among the most prescribed drug in medical ward. Because of the rise in health care cost lack of uniformity in drug prescribing and the emergency of antibiotic resistance monitoring and control of antibiotic use are growing concern and strict antibiotic policies should be warranted. Inappropriate use of antibiotic can increase morbidity, mortality, patient cost and bacterial antibiotic resistance.

Objective: To evaluate antibiotic use practice in medical ward of Fitche hospital, North Showa Zone, Oromia region, Ethiopia.

Methodology: Institution based cross sectional study was conducted by collecting data retrospectively from 200 patient cards drawn by Simple random sampling using balloting from Medical ward of Fitche hospital from March 10May 30, 2016. After checking for completeness and consistency, data was entered in SPSS (IBM 20) and descriptive statistics was carried.

Result: Out of the total 200 patient cards, $110(55 \%)$ were of male and $90(45 \%)$ were of female. Most antibiotics were prescribed for empirical treatment $163(81.5 \%)$ and least for prophylactic treatment $5(2.5 \%)$. In this study, of the total 340 drugs prescribed in Medical ward, the prevalence of antibiotics use was $220(64.7 \%)$. In this study, $65 \%$ received more than one antibiotic. And the most commonly prescribed groups of antibiotic were Cephalosporin $32.5 \%$ and the most commonly prescribed antibiotic was ceftriaxone $27.5 \%$.

Conclusion: This study revealed that of the total of 340 drugs prescribed for 200 patients in Medical Ward of Fitche District Hospital, $64.7 \%$ were antibiotics and the most commonly prescribed groups of antibiotic were Cephalosporin and the most commonly prescribed antibiotic was ceftriaxone. And majority of patients in Medical ward $65 \%$ received more than one antibiotic.
\end{abstract}

\section{Keywords: Drug; Medical ward; Fitche hospital; Antibiotics}

\section{Introduction}

Antibiotics are powerful medicines that fight bacterial infections. Used properly, antibiotics can save lives. They either kill bacteria or keep them from reproducing. Your body's natural defences can usually take it from there [1]. They are one of the pillars of modern medical care and play major role in prophylaxis and treatment of infectious disease. The issue of their availability, selection and proper use are of critical importance to the community antibiotic miser use: however, worldwide with the extent of the problem being greater in the developing countries, through their purchase in local pharmacies and drug stores and through inappropriate prescribing habit and an overzealous desire to treat every infection [2]. They are one of the most common drugs prescribed in hospital today. It has been estimated that up to third of all patients receive at least one antibiotic during hospitalization. The cost involved is there for correspondingly high and up to $40 \%$ of a hospital's drug expenditure may be devoted to the purchase of antibiotics [3,4]. Antimicrobial therapy is administered to $25 \%$ to $40 \%$ of hospital inpatient, and, in $50 \%$ of cases, is inadequate in terms of dosage, rout of administration, or indication Realties such as this strengthen the notion that rational and therefore adequate use of antimicrobial agents plays an essential role in insuring patient safety, particularly in the intensive care setting above all because antibiotic misuse fosters bacterial resistance and increasing the cost of health system [5-7].

In the past decade, there has been an alarming trend towards increase in antimicrobial resistance; there are different factors for the development of antimicrobial resistance: among these; human pathogens, the overuse and inappropriate prescribing of broad spectrum antibiotics has been implicated [8-10]. In the hospital, use of antibiotic drug has been major concern in the last few decades for several reasons for the purchasers of health care service and administration. Antibiotics drugs account for a major proportions of the escalating drug budget. To a greater extent particularly in hospital, the overuse and misuse of antibiotic drug considered to be one of the reasons for increasing resistance among various photogenes: these worries have led to the implementation of strict antibiotic policies in hospital in many countries with different strategies and different outcomes.

Monitoring of drug use is essential in order to follow the effect and adherence to the hospital's antibiotic policies: patient medical record may be reviewed for this purpose. But this method can be quite exhaustive [10]. Excessive and inappropriate use of antibiotic is highly associated with the emergence of antibiotic resistance which presents major threat to global public health. Antibiotic resistance reduce the

*Corresponding author: Addisu Alemayehu Gube, Department of Nursing College of Medicine and Health Sciences, Arbaminch University, Ethiopia, Tel: +251-9-12119726; Fax: +251-46-8810279; E-mail: addis166@gmail.com

Received August 10, 2017; Accepted August 22, 2017; Published August 26, 2017

Citation: Gube AA, Gonfa R, Tadesse T (2017) Evaluation of Antibiotic Use in Medical Ward of Fitche District Hospital, North Showa Zone, Oromia Region, Ethiopia. Adv Pharmacoepidemiol Drug Saf 6: 216. doi: 10.4172/21671052.1000216

Copyright: $\odot 2017$ Gube AA, et al. This is an open-access article distributed under the terms of the Creative Commons Attribution License, which permits unrestricted use, distribution, and reproduction in any medium, provided the original author and source are credited. 
effectiveness of and number of option for antibiotic treatment, leading to increased morbidity, mortality, and health care expenditure $[11,12]$. Growing misuse of antibiotics has been reported in hospitals, causing toxic effects and various infections due to resistant microorganisms that increase the cost and duration of hospitalization. Increased cost of health care will definitely jeopardizes the capacity of the poor population to seek the modern health care. There is a pressing need to develop appropriate measures to curtail misuse of drugs in general and antibiotics in particular. Besides; a drug use in hospitals has a considerable influence on further drug use outside the hospitals [13].

Several strategies for controlling antibiotic usage have been proposed. Such as formulary replacement or restriction, introduction order form, health care provider education, feedback activates, and approval requirement from infectious disease specialist for drug prescription [14,15]. Drug Use Evaluation (DUE) is an ongoing systematic process designed to maintain the appropriate and effective use of drug. It incorporates qualitative measure and emphasizes outcome. Including pharmacoeconomics assessment. DUE can identify problem in drug use, reduce adverse drug reaction, optimize drug therapy and minimize drug related expense it often include intervention to ensure appropriate drug use [16]. Drug use evaluation focuses on the area that show greater potential for improvements. It involve on compressive review of patient prescription and medication data, during and after dispensing in order to ensure appropriate therapeutic decision making and promote positive outcome [17].

In Ethiopia, particularly in Fitche, there are no sound studies conducted about the evaluation of antibiotics use in hospital wards. Therefore, this study was designed to evaluate use of antibiotics in medical ward of Fitche hospital, North Showa Zone, Oromia region, Ethiopia.

\section{Methods and Materials}

\section{Study are and period}

The study was conducted in Fitche hospital North Showa Zone, Oromia region, which is found $115 \mathrm{~km}$ from Addis Ababa. Its total population is 27,493 in numbers of which 12,933 are males and 14,560 are females. The town has many governmental and privet organization such as Government hospital and health center. Fitche hospital has different departments and wards like OPD, medical, gynecology, pediatrics, and surgical ward. And the study focused in Medical ward of the hospital. The study was conducted from March 10 to May 30, 2016.

\section{Study design}

Institution based cross sectional study was conducted by collecting data retrospectively from patient card in Medical ward of Fitche hospital.

\section{Source population}

All patients who are admitted/referred/discharged/died in Medical Ward of Fitche hospital.

\section{Study population}

All patients who are admitted in medical ward and who have taken at least one antibiotic with or without concurrent medication and admitted, referred, discharged, or died in the study period.

\section{Sampling size and sampling technique}

The sample size for this study was calculated using single population proportion formula based on the following Assumptions: $\mathrm{p}=50 \%$, with $95 \%$ confidence level and $5 \%$ level of precision. So, total of 384 was calculated and since, the number of population was less than 10,000 , the correction formula was used and the sample size became: 200 patient cards.

From the total cards of patients who admitted to a medical ward from September 10, 2015 to May 10, 2016 and fulfill the inclusion criteria, 200 patient cards were selected by Simple random sampling using balloting.

\section{Data processing and analysis}

After checking for completeness and consistency, data was entered in SPSS (IBM 20) and descriptive statistics was carried. And data were presented using narratives, tables and figure.

\section{Ethical consideration}

A formal letter was written from Ambo University, College of Medicine and Health Sciences, department of Pharmacy to Fiche Hospital in order to get permission to conduct the study. And Fitch Hospital Administrators were notified about the objective of the study and the confidentiality of patient cards.

\section{Results}

\section{Socio demographic characteristics}

The most age group treated by antibiotics were $15-25$ year of age which accounts $61(30.5 \%)$. While the least age group treated by antibiotics were those of greater than 70 year of age. Of the patients, $110(55 \%)$ were males and 90 (45\%) were females (Table 1 ).

\section{Patterns of antibiotic prescribing}

In this study, the total of 340 drugs including antibiotics were prescribed to the total of 200 patients; out of which 220 (64.7\%) were antibiotics. From the total of antibiotics, Ceftriaxone 55 (27.5\%) was the most frequently prescribed antibiotics followed by doxycycline 40 (20\%); Ciprofloxacin $23(11.5 \%)$ and Cephalexin was prescribed for only 2 (1\%) patient (Tables 2 and 3 ).

In this study, from the total of 200 patients, many of the patients are treated by two antibiotics: $84(42 \%), 70(35 \%)$ receive one antibiotics and the rest $46(23 \%)$ receive three antibiotics (Figure 1).

With regard to purpose of antibiotic prescribing, this study revealed that majority of antibiotics were prescribed for empirical treatment 163 (81.5\%), followed by kinetic treatment $32(16 \%)$ and prophylactic use accounted the least 5(2.5\%) (Figure 2).

\begin{tabular}{|c|c|c|}
\hline Variables & Frequency & Percentage \\
\hline \multicolumn{3}{|c|}{ Sex } \\
\hline Male & 110 & $55 \%$ \\
\hline Female & 90 & $45 \%$ \\
\hline \multicolumn{3}{|c|}{ Age } \\
\hline $15-25$ & 61 & $30.5 \%$ \\
\hline $26-36$ & 43 & $21.5 \%$ \\
\hline $37-47$ & 35 & $17.5 \%$ \\
\hline $48-58$ & 25 & $12.5 \%$ \\
\hline $59-69$ & 21 & $10.5 \%$ \\
\hline $70-80$ & 15 & $7.5 \%$ \\
\hline
\end{tabular}

Table 1: Socio demographic characteristics of patients in Medical ward of Fiche District Hospital. 
Citation: Gube AA, Gonfa R, Tadesse T (2017) Evaluation of Antibiotic Use in Medical Ward of Fitche District Hospital, North Showa Zone, Oromia Region, Ethiopia. Adv Pharmacoepidemiol Drug Saf 6: 216. doi: 10.4172/2167-1052.1000216

Page 3 of 4

\begin{tabular}{|c|c|c|}
\hline Antibiotics Groups & Frequency & Percentage (\%) \\
\hline Cephalosporin & 65 & $32.5 \%$ \\
\hline TTC & 40 & $20 \%$ \\
\hline Flour quinolone & 37 & $18.5 \%$ \\
\hline Metronidazole & 21 & $10.5 \%$ \\
\hline CAF & 17 & $8.5 \%$ \\
\hline Cotrimoxazole & 6 & $3 \%$ \\
\hline Aminoglycoside & 7 & $3.5 \%$ \\
\hline Penicillin & 4 & $2 \%$ \\
\hline Augmentin & 3 & $1.5 \%$ \\
\hline Total & 200 & $100 \%$ \\
\hline
\end{tabular}

Table 2: Most commonly prescribed group of antibiotics in medical ward of Fitche District Hospital.

\begin{tabular}{|c|c|c|}
\hline Antibiotics & Frequency & Percentage (\%) \\
\hline Ceftriaxone & 55 & $27.5 \%$ \\
\hline Doxycycline & 40 & $20 \%$ \\
\hline Ciprofloxacin & 23 & $11.5 \%$ \\
\hline Metronidazole & 21 & $10.5 \%$ \\
\hline Chloramphenicol & 17 & $8.5 \%$ \\
\hline Norfloxacine & 14 & $7 \%$ \\
\hline Cloxacillin & 8 & $4 \%$ \\
\hline Cotrimoxazole & 6 & $3 \%$ \\
\hline Gentamycin & 4 & $2 \%$ \\
\hline Ampicillin & 4 & $2 \%$ \\
\hline Clarithromycin & 3 & $1.5 \%$ \\
\hline Augmentin & 3 & $1.5 \%$ \\
\hline Cephalexin & 2 & $1 \%$ \\
\hline Total & 200 & $100 \%$ \\
\hline
\end{tabular}

Table 3: Most commonly prescribed antibiotics in medical ward of Fitche District Hospital.

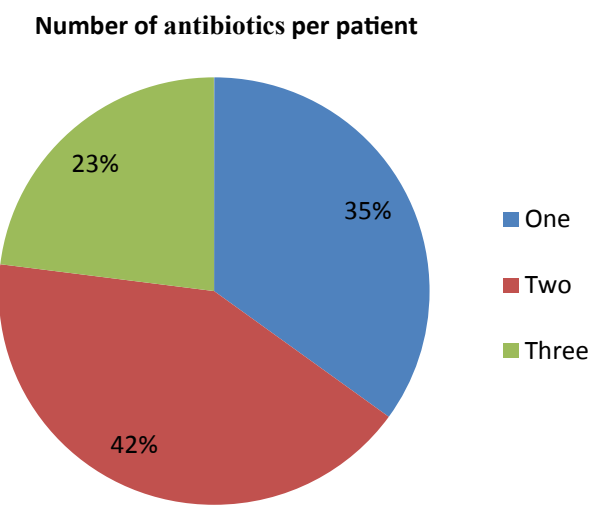

Figure 1: Number of antibiotics prescribed per patient in medical ward of Fitche District Hospital.

According to this study Community Acquired Pneumonia (CAP) was the most commonly distributed disease which account $61(30 \%)$ followed by meningitis $38(19 \%)$ and Acute Gastroenteritis (AGE) 25(12\%) (Table 4).

In this study, when we see the duration of hospitalization for 200 patients, 80 (40\%) stay for 1-4 days, 65 (32.5\%) for 5-9 days, 30 (15\%) for 10-14 days, 20 (10\%) stay for 15-19 days and 5 (2.5\%) stay for greater than 20 days in hospital.

\section{Route of administration and potential drug-drug interaction}

In this study out of 220 prescribed antibiotics for 200 patients, most

of them prescribed in IV route which account 76(38.2\%), followed by PO 68(34.1\%) and IM 16 (6.3\%) (Table 5).

\section{Appropriateness of antibiotic use}

When we see the appropriateness of the antibiotic use with respect to dose, frequency and duration, the study revealed that 181 (90.5\%), $194(97 \%)$ and $186(93 \%)$ were corresponds to appropriate dose, frequency and duration respectively and $14(7 \%), 5(1.5 \%)$ and $10(5 \%)$ were inappropriate dose, frequency and duration respectively.

\section{Discussion}

This institution based cross sectional study has investigated antibiotic use in Medical ward of Fitche District Hospital, North Showa Zone, Oromia Region, Ethiopia.

The use of antibiotics in medical ward is justifiable practice even though it requires a regular review of the chosen regimen to maximize the benefit of the patient. In this study, of the total 340 drugs prescribed in Medical ward, the prevalence of antibiotics use was 220 (64.7\%). This finding is lower than the finding of the study conducted

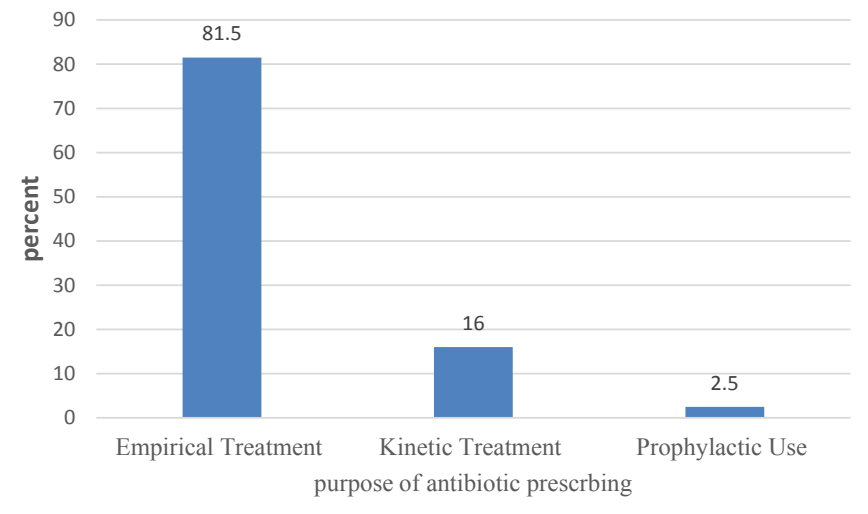

Figure 2: Antibiotic treatment types in medical ward of Fiche District Hospital.

\begin{tabular}{|c|c|c|c|}
\hline S. No. & Disease & Frequency & Percentage \\
\hline 1 & CAP & 61 & $30 \%$ \\
\hline 2 & Meningitis & 38 & $19 \%$ \\
\hline 3 & AGE & 25 & $12 \%$ \\
\hline 4 & UTI & 23 & $11.5 \%$ \\
\hline 5 & AFI & 13 & $6.5 \%$ \\
\hline 6 & Typhoid & 9 & $4.5 \%$ \\
\hline 7 & Septic arthritis & 8 & $4 \%$ \\
\hline 8 & Cellulitis & 7 & $3.5 \%$ \\
\hline 9 & PUD & 6 & $3 \%$ \\
\hline 10 & Rheumatic arthritis & 6 & $6 \%$ \\
\hline 11 & Other & 4 & $2 \%$ \\
\hline & Total & 200 & $100 \%$ \\
\hline
\end{tabular}

Table 4: Distribution of common disease for which antibiotics were prescribed in medical ward of Fitche District Hospital.

\begin{tabular}{|c|c|c|}
\hline Route & Frequency & Percentage \\
\hline IV & 84 & $38.2 \%$ \\
\hline IV+PO & 31 & $14.1 \%$ \\
\hline PO & 75 & $34.1 \%$ \\
\hline IM & 16 & $7.3 \%$ \\
\hline IM+PO & 14 & $6.3 \%$ \\
\hline
\end{tabular}

Table 5: Route of administration of antibiotics in medical ward of Fitche Hospital. 
Citation: Gube AA, Gonfa R, Tadesse T (2017) Evaluation of Antibiotic Use in Medical Ward of Fitche District Hospital, North Showa Zone, Oromia Region, Ethiopia. Adv Pharmacoepidemiol Drug Saf 6: 216. doi: 10.4172/2167-1052.1000216

Page 4 of 4

in Debremarkos Referral Hospital, Northwest Ethiopia where the prevalence of antibiotics use was $71.36 \%$ [18]. This might be because the study carried out in Debremarkos was carried in the whole Referral hospital and shows the findings from all departments where as our study only focused in medical ward of Fitche district hospital.

The finding of this study is higher than the finding of the study conducted in Dessie Referral hospital, Northeast Ethiopia, where the prevalence of antibiotics use was $24.37 \%$ [19]. This might be because this study is carried out in outpatient pharmacies and the time gap between the two studies. In this study, of the total 200 patients treated at Medical ward of Fitche district hospital, majority of them $65 \%$ received more than one antibiotic. This finding is almost comparable with the finding of the study conducted in Ayder Referral hospital, Mekelle Ethiopia, where majority of patients $58.8 \%$ in the hospital received more than one antibiotic. Although the simultaneous use of two or more antibiotics has a certain rational, indiscriminate or routine use of antibiotic combination may have several negative consequences: primarily, the patient Risk of toxicity from two or more antibiotics, increased cost and the emergence of drug resistance.

In this study, the most commonly prescribed groups of antibiotic were Cephalosporin $32.5 \%$ and the most commonly prescribed antibiotic was ceftriaxone $27.5 \%$. This findings is almost similar with the finding of the study conducted in Ayder Referral hospital, Mekelle Ethiopia, where the most commonly prescribed groups of antibiotics and the most commonly prescribed antibiotic were Cephalosporin $32.7 \%$ and ceftriaxone $28.7 \%$ respectively.

\section{Conclusion and Recommendations}

\section{Conclusion}

This study revealed that of the total of 340 drugs prescribed for 200 patients in Medical Ward of Fitche District Hospital, 64.7\% were antibiotics and the most commonly prescribed groups of antibiotic were Cephalosporin and the most commonly prescribed antibiotic was ceftriaxone. And majority of patients in Medical ward 65\% received more than one antibiotic.

\section{Recommendations}

District health office and Fitche Hospital should work together in order to oversee and control antibiotics use in the hospital, Medical ward in particular. They have to make sure whether standard and national guidelines are being followed during using antibiotics in the hospital.

\section{Acknowledgement}

The authors' sincere thanks go to Ambo University for provision of the opportunity to conduct the research. They also like to give their deepest gratitude for Fitche District hospital staffs for their cooperation in providing basic information. Lastly their thanks go to Medical Record Room workers and all research participants who took part in the study.

\section{References}

1. Antibiotics (2016) U.S. National Library of Medicine.

2. Ibewuchi R, Mbata T (2002) Rational and irrational use of antibiotics. Africa Health 24: 16-18.

3. Lim VK, Cheong YM, Suleiman AB (1993) Pattern of antibiotic usage in hospitals in Malaysia. Singapore Med J 34: 525-528.

4. http://apps.who.int/medicinedocs/en/d/Js2289e/

5. Correa L (2007) Restriction to the use of antimicrobials in the hospital environment. Einstein: Continuing Education in Health 5: 48-52.

6. Eickhoff T (1992) Antibiotics and nosocomial infections. In: Bennet J, Brachman P (eds.) Hospital Infections ( $3^{\text {rd }}$ edn.). Brown and Company, Boston pp: 245-264.

7. Neu H (1993) Antimicrobialagent: role in prevention and control nosocomial infections. In: Wenzel R (ed.) Prevention and Control of Nosocomial Infection $\left(2^{\text {nd }}\right.$ edn. $)$. Williams and Wilkins, Baltimore pp: 406-441.

8. Dranitstaris G, Brook's J, McGeer A, landry L, Loeb M (1998) Assessment in health care Meeting. InSocTechnol.

9. http://www.who.int/drugresistance/infosharing/AMR_WS_WERNIGERODE_ REPORT_EURO.pdf

10. Kivert R, Dahl M, Llerena A, Maimets M, Wettermark B et al. (1998) Antibiotic use in 3 European University Hospital. Scand J infects Dis 30: 277-280.

11. Fishman N (2006) Antimicrobial stewardship. Am J Med 119: S62-S70.

12. Smith RD, Coast $J$ (2002) Antimicrobial resistance: A global response. Bull World Health Org 80: 126-133.

13. Gyssen IC, Blok W, vanden Broek PJ, HeksterYA, vander Meer JW (1997) Implementation of an educational program and an antibiotic order form to optimize quality of antimicrobial drug use In a department Internal medicine. Eur J Clin Microbiol Infect Dis 16: 904-912.

14. Guglielemo BJ (1995) Practical strategies for the appropriate use of antimicrobial. Pharm World Sci 17: 96-102.

15. Phillips MS, Gayman JE, Todd MW (1996) ASHP guidelines on medication-use evaluation. American Society of Health-system Pharmacists. Am J Health Syst Pharm 53: 1953-1955

16. Robert J, Pean Y, Varon E, Bru JP, Bedos JP, et al. (2012) Point prevalence survey of antibiotic use in French hospitals in 2009. J Antimicrob Chemother 67: 1020-1026.

17. Tigestu AD, Tesfahun CE (2014) Assessment of drug use pattern using World Health Organization core drug use indicators at Debremarkos Referral Hospital, Northwest Ethiopia. Int J Innovat Pharmaceut Sci Res 2: 2347-2154.

18. Endale G, Solomon A, Wuletaw A, Asrat A (2013) Antibiotic prescribing pattern in a referral hospital in Ethiopia. Afr J Pharm Pharmacol 7: 2657-2661.

19. Solomon A, Rahel A, Fantahun M, Melkam W, Assen A, et al. (2015) Antibiotics utilization and their cost in Ayder Referral Hospital, Mekelle, Ethiopia. Glob J Med Res 15. 